\section{Empirical modelling for retrieval of foliar traits in cotton crop using spatial data}

\author{
Ramandeep Kaur M. Malhi and \\ G. Sandhya Kiran* \\ Ecophysiology and RS-GIS Lab, Department of Botany, \\ Faculty of Science, The Maharaja Sayajirao University of Baroda, \\ Vadodara 390 002, India
}

The present study conducted in cotton fields of Vadodara district, Gujarat, India during kharif season of 2009-10, aimed at assessing foliar traits, in particular crop leaf area index (LAI) and chlorophyll content (CC) from space-borne optical LANDSAT 5 TM and IRS LISS-IV satellite data. Field measurements of these foliar traits coinciding with the dates of the satellite data for cotton were used for validation of RSbased VI-LAI and VI-CC empirical models developed in the present study. These models developed for LAI estimation in cotton crop showed good correlation with $R^{2}$ varying from 0.592 to 0.805 , and $C C$ between 0.585 and 0.746 with $P$ at 0.01 level in both cases. It has been observed that the potential of NDVI-LAI and NDVI-CC empirical models was better compared to RVI-LAI and RVI-CC models. The VI-LAI and VI-CC models derived from LISS-IV data were better estimators of LAI compared to LANDSAT. A high $\boldsymbol{R}^{2}$ value between ground-measured foliar traits and those predicted using empirical models complemented the validation.

Keywords: Cotton crop, empirical models, foliar trait, spatial data.

AGRICUltURAL, ecological and meteorological applications require an accurate quantitative estimation of canopy foliar traits - in particular vegetation biochemical and biophysical variables ${ }^{1,2}$. Information about the spatial and temporal distribution of these traits provides an important input for various models quantifying the exchange of energy and matter between the land surface and the atmosphere. The knowledge of these traits is of prime interest in many applications related to crop function modelling, evapotranspiration, crop growth modelling and yield prediction. These traits also aid in predicting the soil-vegetation-atmosphere energy transfers. Even at a much smaller scale, as in precision farming and water management, these traits play a critical role to describe the state of crop development and water needs. Measurement of these traits during the growing season also provides an opportunity for improving grain yields and quality by site-specific application of fertilizers. Among

\footnotetext{
*For correspondence. (e-mail: ecorsgis12@gmail.com)
}

the many canopy foliar traits, leaf area index (LAI) and chlorophyll content (CC) are of prime importance.

LAI, an important biophysical parameter characterizing a canopy, is the total one-sided area of leaf tissue per unit ground surface area ${ }^{3}$. It has a key role as one of the surface parameters in climate, weather and ecological studies as it influences vegetation photosynthesis, transpiration and the energy balance of canopies ${ }^{4}$. It serves as an important input to the ecosystem productivity models operating at landscape to global scales ${ }^{5}$, and also as an interacting component in general circulation models ${ }^{6}$. Estimation of LAI is critical for understanding and quantitatively analysing many physical and biological processes that are related to vegetation dynamics, global carbon cycle and climate.

Chlorophyll is the earth's most important organic molecule and one of the most important biochemicals in the leaves of plants. The $\mathrm{CC}$ within a vegetation canopy is positively related to both vegetation productivity and its health ${ }^{7}$. It holds significance since it controls photosynthetic potential ${ }^{8}$ and, consequently, primary production as $\mathrm{CC}$ has a dominant control upon the amount of solar radiation absorbed by the leaves ${ }^{9}$. It is also an important indicator of nutritional stress ${ }^{10-13}$. Thus estimation of CC can provide an accurate and indirect estimate of plant nutrient status, especially nitrogen, because the molecular structure of chlorophyll incorporates a large proportion of total leaf nitrogen ${ }^{14-16}$. CC in leaves is an indicator of nitrogen content, as it is dependent on soil nitrogen availability to a great extent and also on crop nitrogen uptake. Hence, this foliar trait in agricultural fields can prove to be of immense use. Estimates of this parameter can help farmers and agronomists make management decisions related to nitrogen supply at critical growth stages.

Undoubtedly conventional methods of estimating LAI and $\mathrm{CC}$ are cumbersome, tedious, time-consuming at the global scale. In this context, information regarding these traits extracted from satellite data has better potential ${ }^{17,18}$. Approaches for the estimation of $\mathrm{CC}$ and LAI from remotely sensed data are based either on the inversion of physically based models ${ }^{19-27}$ or improved relationships between these traits and spectral indices ${ }^{28-37}$. In the former model approach, simulation of canopy reflectance is performed, followed by quantitative relationships between remotely sensed data and canopy attributes for inversion purposes. Approaches using spectral indices rely on the establishment of empirical relationships between groundmeasured foliar traits and observed spectral reflectances.

Vegetation index (VI)-LAI and VI-CC models for cotton crop using LANDSAT 5 TM and IRS LISS-IV reflectance data have been developed in the present study.

The study was conducted in the cotton fields of Vadodara district, Gujarat, India (Figure 1). The district lies between $21^{\circ} 45^{\prime}-22^{\circ} 45^{\prime} \mathrm{N}$ and $72^{\circ} 48^{\prime}-74^{\circ} 15^{\prime} \mathrm{E}$, having a geographical area of $7550 \mathrm{sq}$. km. Major part of the 


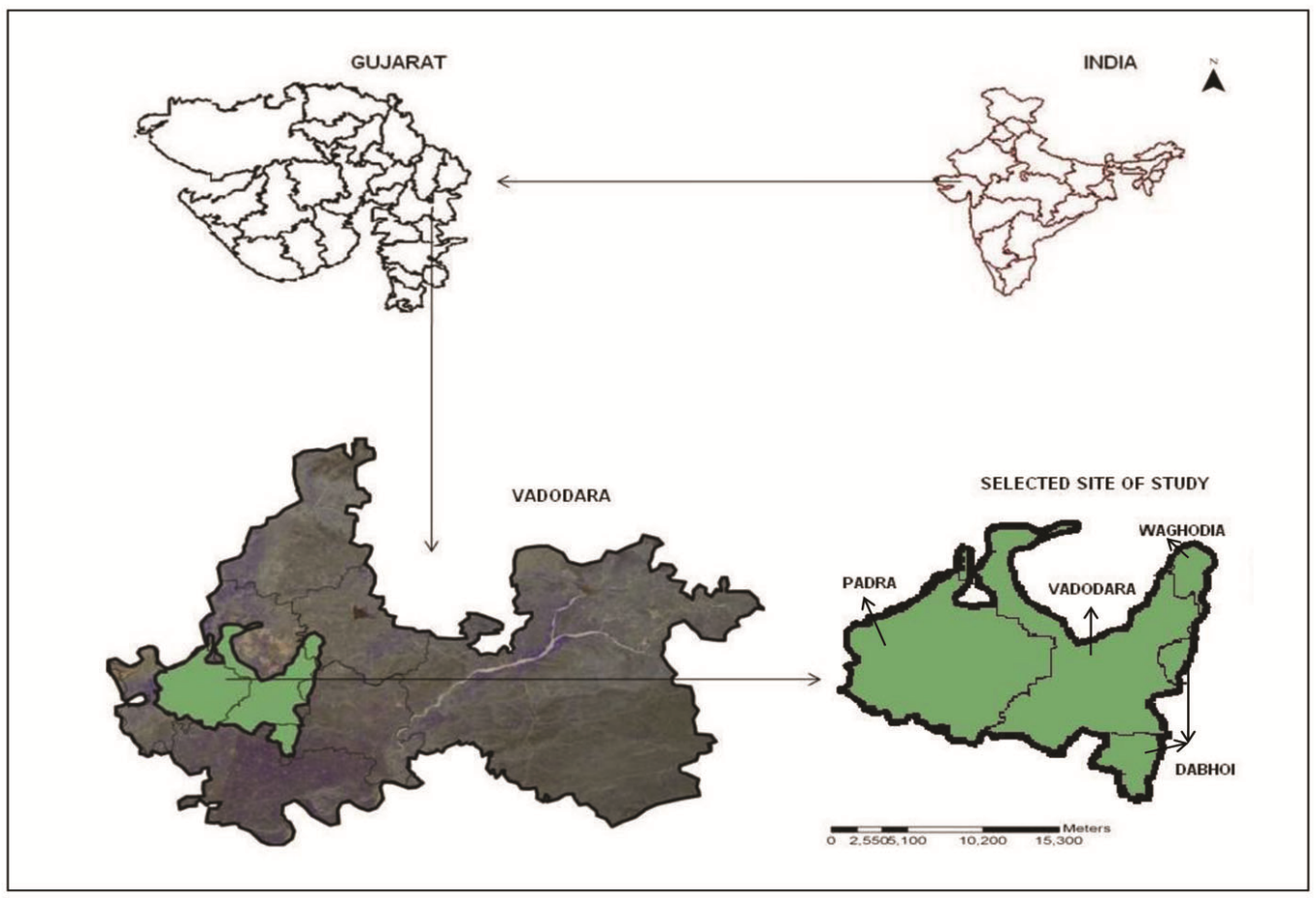

Figure 1. Map showing location of the study area.

study area is covered by alluvial soil which is fertile and thus suitable for agriculture.

Generally, the climate of Vadodara district during major part of the year is characterized by a hot weather and humidity. During winter season, it is not too cold in the district with temperature remaining over $10^{\circ} \mathrm{C}$. January is the coldest month of the year, with mean daily maximum and minimum temperature of $30.1^{\circ} \mathrm{C}$ and $10.8^{\circ} \mathrm{C}$ respectively. It is hot during March to October, with temperatures hovering over $35^{\circ} \mathrm{C}$, with little respite during monsoon in June, which lasts till the end of September. May is the hottest month of the year with mean daily maximum and minimum temperature of $40.7^{\circ} \mathrm{C}$ and $26.1^{\circ} \mathrm{C}$ respectively. During the last ten years, average rainfall has been recorded in the range of 1000-1200 mm. October and November are considered as the postmonsoon period.

Based on India Meteorological Department (IMD) data, it was observed that predominant wind direction during winter season (October-April) was from northeast and northwest directions, whereas during summer, it was from west and southwest directions. The general weather conditions were conducive to good agriculture (both $\mathrm{kha}$ rif and rabi harvest).

LAI of cotton crop was measured using the plant canopy analyser (LAI-2000; LI COR Inc., Lincoln, NE, USA). This is a portable field instrument that simultaneously measures diffuse radiation using fisheye technique, with the optical sensors arranged in concentric rings in five distinct angular bands, and central zenith angles of $7^{\circ}$, $23^{\circ}, 38^{\circ}, 53^{\circ}$ and $68^{\circ}$. The basic technique involves measuring sky brightness from a levelled sensor above the canopy and a second measurement below the canopy, with the sensor viewing towards sky ${ }^{38}$.

LAI measurements were taken at six random locations within each field, where each observation was the average of six point measurements. The measurements were carried out under uniform clear diffuse skies at low solar elevation to prevent the effects of direct sunlight on the sensor.

A portable chlorophyll meter (SPAD-502; Minolta Corporation, New Jersey, USA) was used to measure leaf CC. However, the instrument does not provide the actual contents of chlorophyll per unit area of leaf tissue; instead it gives data only in arbitrary units. In the present study, a standard method was used for determination CC in leaf samples of cotton crop. Homogenization of the leaf tissue in $80 \%$ acetone was carried out and then absorbance at 663 and $645 \mathrm{~nm}$ was measured. Then, specific absorption coefficients for chlorophyll $a$ and $b$, provided by Arnon ${ }^{39}$ were used for the calculation of CC (ref. 40).

LAI and CC measurements were carried out corresponding to the selected satellite pass time.

LANDSAT 5 TM and LISS-IV data were used for the study. The pixel reflectances were extracted in the red and NIR bands within the region of interest (ROI) centred on cotton fields, where LAI and CC measurements were taken. Mean values for red and NIR reflectances for each ROI were computed. 
Table 1. Vegetation indices used in the study

\begin{tabular}{llc}
\hline Index & \multicolumn{1}{c}{ Equation } & Reference \\
\hline $\begin{array}{l}\text { Normalized difference vegetation index (NDVI) } \\
\text { Ratio vegetation index (RVI) }\end{array}$ & NDVI $=(\mathrm{NIR}-$ red $) /(\mathrm{NIR}+\mathrm{red})$ & 57 \\
\hline
\end{tabular}

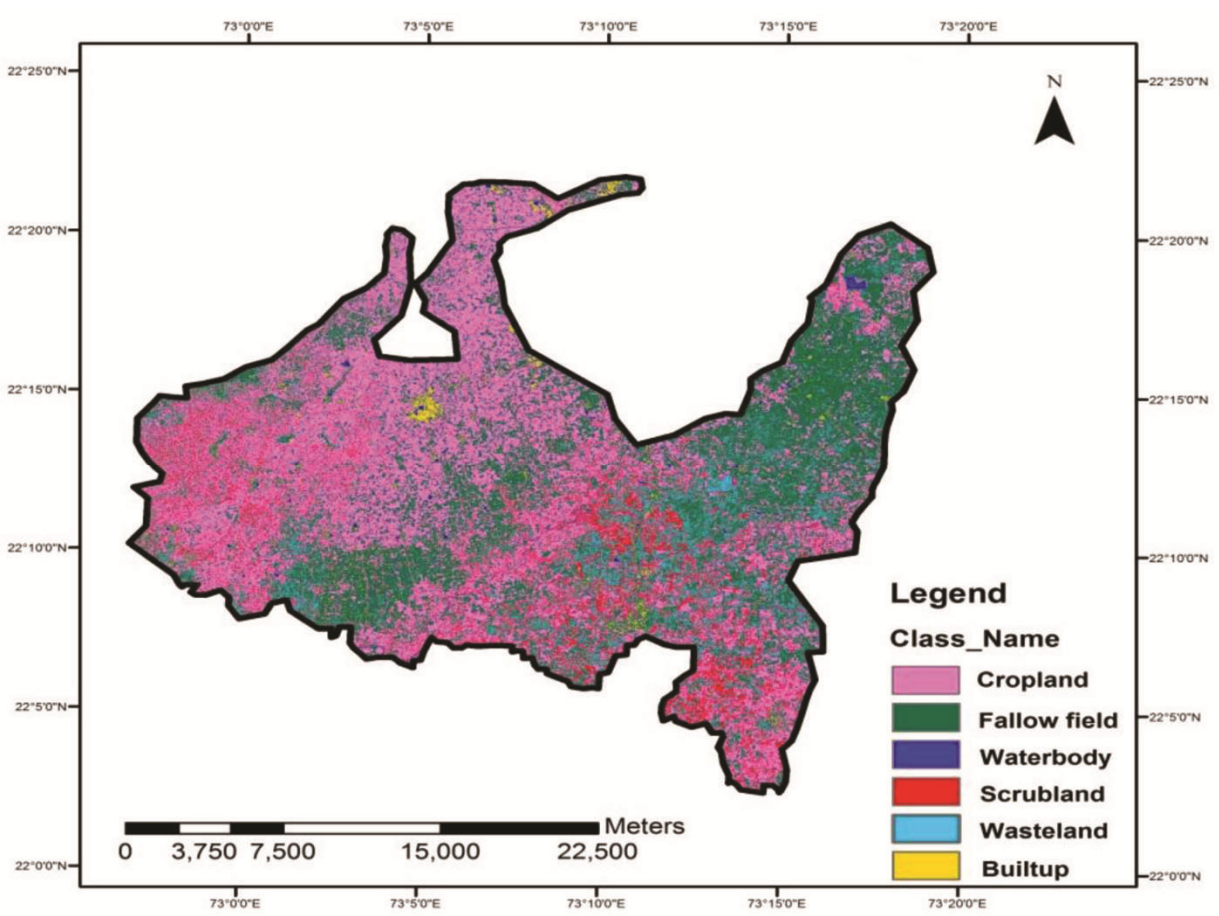

Figure 2. Land-use map generated using LISS-IV data for October 2009.

For retrieval of the foliar traits from optical satellite data, empirical statistical approach was adopted. The methodology involves two steps: (1) Extracting spectral indices from optical satellite images. (2) Establishing relationships between extracted spectral indices and ground-measured foliar traits.

Vegetation indices considered to be good candidates for estimating LAI and CC were tested. These were developed from the reflectance bands of the optical data using ERDAS-9.1. Table 1 shows two vegetation indices computed from the selected optical satellite images.

The gathered datasets of indices and foliar traits (namely LAI and CC) were statistically analysed to determine correlations and derive empirical relationships between crop LAI and VI; and leaf CC and VI. Each calculated VI was linearly related to different LAI values. Similarly, extracted values for each VI were also linearly related to $\mathrm{CC}$. Accuracy assessment and validation of the developed models were also carried out.

To understand overall scenario of the study area, initially land-use classification was carried out which provided a precise information on the total contribution of agricultural land in the study area (Figure 2). The data generated showed $78.7 \%$ of land under agriculture, which included both cropland and fallow field categories with an overall accuracy of $93.3 \%$ and kappa statistics as 0.89 .

Crop-type classification showing cotton area in the entire study region was found to be subtle, despite high resolution due to field heterogeneity resulting into mixing of signatures. Several workers have also reported such difficulties in crop-type classification due to small-scale traditional agricultural holdings, such as the densely populated rural landscapes of India ${ }^{41,42}$. Small agricultural fields and diversity in crop types are the components contributing to subtleness in crop-type classification while mapping large areas.

In situ LAI values in the cotton fields captured the data range $0.2-4.76$, around a total mean value of 2.59 . CC ranged from 9.07 to $22.47 \mathrm{mg} \mathrm{g}^{-1}$, with mean value of $15.8 \mathrm{mg} \mathrm{g}^{-1}$. NDVI and RVI values for cotton crop extracted from LANDSAT $5 \mathrm{TM}$ and LISS-IV data are shown in Table 2, which serve as an input for the retrieval of cotton foliar traits, viz. LAI and CC.

Linear models developed for the assessment of LAI in cotton crop by correlating it with LANDSAT and LISSIV-derived NDVI and RVI showed good correlations. Chlorophyll also showed good correlation with the extracted indices. Coefficient of determination $\left(R^{2}\right)$ for 
Table 2. Extracted vegetation indices from LANDSAT 5 TM and LISS-IV data

\begin{tabular}{llccccc}
\hline & & \multicolumn{3}{c}{ NDVI } & & \multicolumn{2}{c}{ RVI } \\
\cline { 3 - 4 } \cline { 6 - 7 } Crop & Satellite data & Range & SD & & Range & SD \\
\hline \multirow{2}{*}{ Cotton } & Landsat 5 TM & $0.11-0.42$ & 0.07 & & $1.0-2.7$ & 0.33 \\
& LISS-IV & $0.13-0.45$ & 0.08 & & $1.1-2.7$ & 0.43 \\
\hline
\end{tabular}

(a)

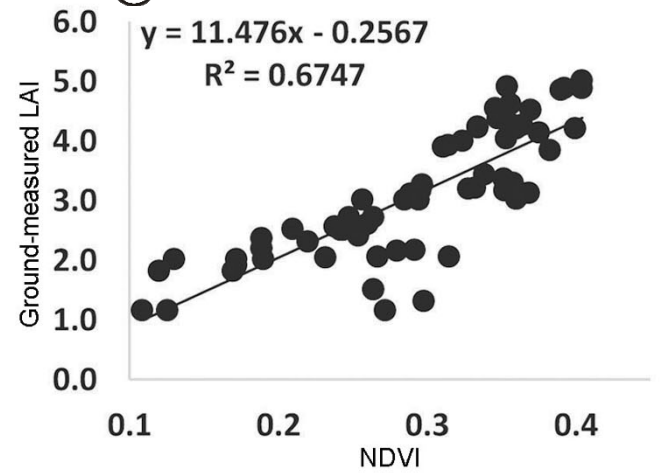

(c)

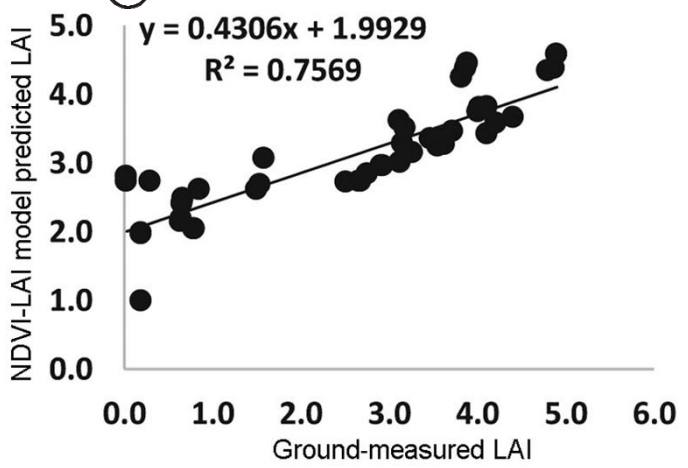

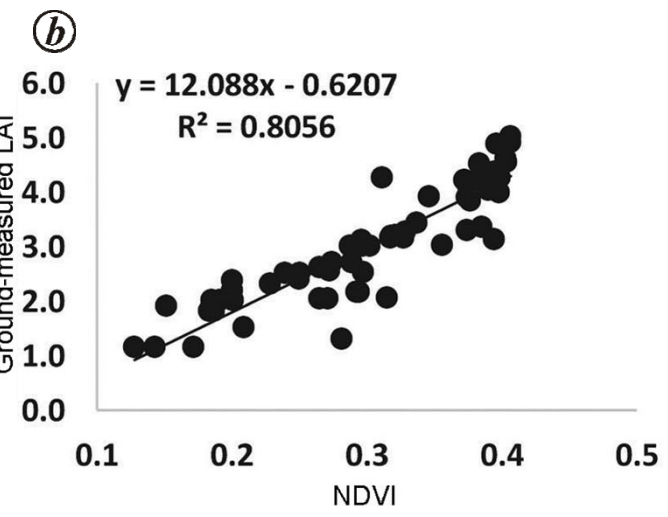

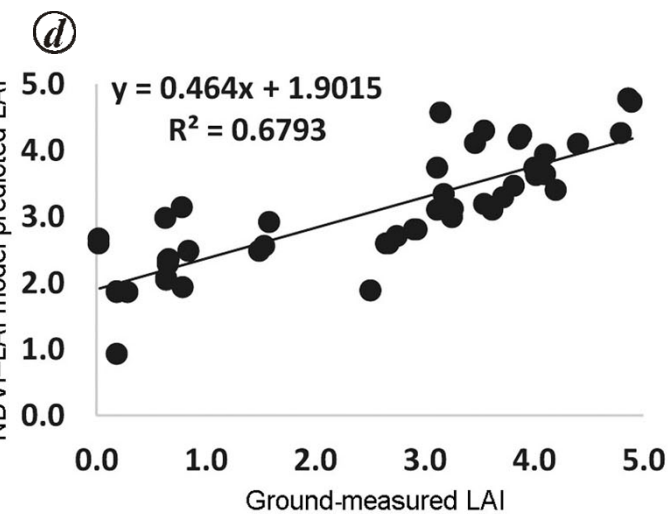

Figure 3. $\boldsymbol{a}$, Linear relationship between LANDSAT NDVI and cotton leaf area index (LAI); $\boldsymbol{b}$, Linear relationship between LISS-IV NDVI and cotton LAI; $\boldsymbol{c}$, Validation of Landsat NDVI-LAI model using ground-measured cotton LAI; $\boldsymbol{d}$, Validation of LISS-IV NDVI-LAI model using ground measured cotton LAI.

these models varied from 0.585 to 0.805 . RS-based empirical models generated from spatial indices for the retrieval of foliar traits have also been reported by earlier researchers ${ }^{43-45}$. They have confirmed that the retrieval of these traits using vegetation indices such as NDVI and RVI can be achieved with an acceptable accuracy.

For any established statistical model, its validation becomes important with respect to algorithm development for large-scale applications ${ }^{46}$. Validation carried out for all the developed models exhibited strong relationship between estimated and predicted foliar traits.

NDVI-LAI model: The correlation of LAI with LISS-IV NDVI was comparatively higher with $R^{2}=0.805$ (Figure $3 b$ ) when compared to that with LANDSAT NDVI with $R^{2}=0.674$ (Figure $3 a$ and $b$ ). The $t$-test conducted for correlation coefficient showed that the results are highly significant at $P=0.01$ level. Validation of both the
LANDSAT NDVI-LAI and LISS-IV NDVI-LAI models showed a good relationship between ground-measured LAI and NDVI-LAI-predicted LAI (for LANDSAT data, $R^{2}=0.756$ and for LISS-IV data $R^{2}=0.679$; Figure $3 c$ and $d$ ). A good accuracy of $92.7 \%$ and $87.8 \%$ was observed for the developed LANDSAT and LISS-IV data based biophysical models respectively.

RVI-LAI model: The linear regression relationships established between in situ cotton LAI and LANDSAT RVI showed comparatively less but good positive correlation (Figure $4 a)\left(R^{2}=0.592\right)$ than LISS-IV RVI which showed better correlation with in situ LAI (Figure $4 b)\left(R^{2}=\right.$ $0.696)$. Results for these correlations are highly significant $(P=0.01$ level). Validation carried out for RVI-LAI models showed significant correlation between groundmeasured LAI and RVI-LAI model-predicted LAI (Figure $4 c$ and $d$ ). RVI-LAI model established using LANDSAT 

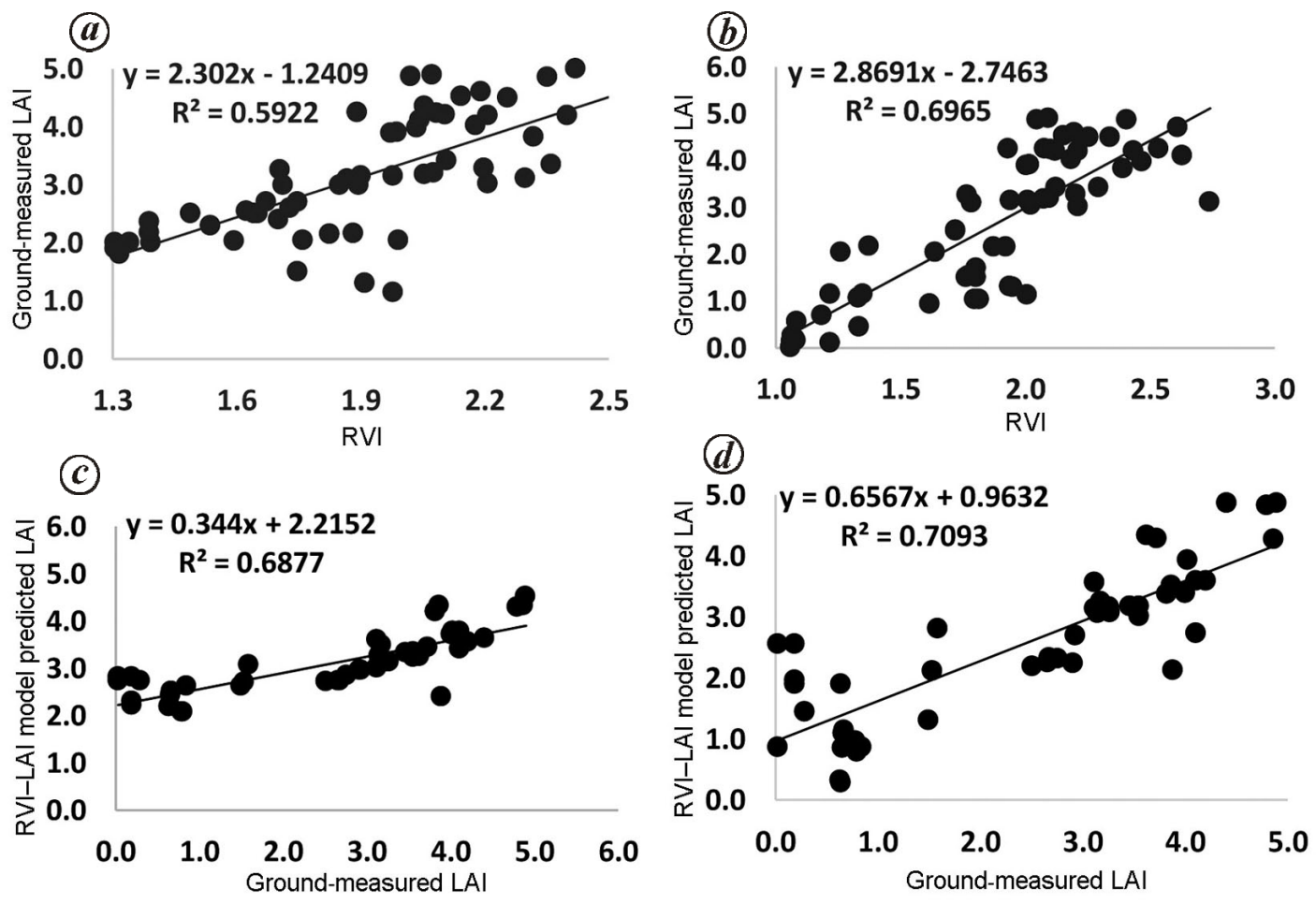

Figure 4. $\boldsymbol{a}$, Linear relationship between LANDSAT RVI and cotton LAI; $\boldsymbol{b}$, Linear relationship between LISS-IV RVI and cotton LAI; $\boldsymbol{c}$, Validation of LANDSAT RVI-LAI model using ground-measured cotton LAI; $\boldsymbol{d}$, Validation of LISS-IV RVI-LAI model using ground-measured cotton LAI.

(a)

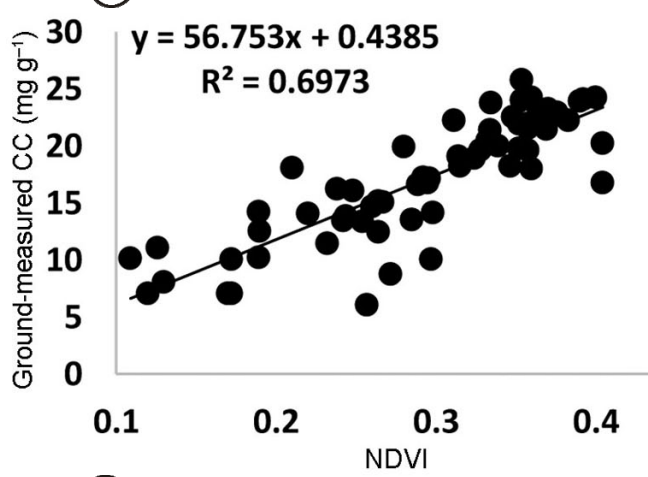

(c)

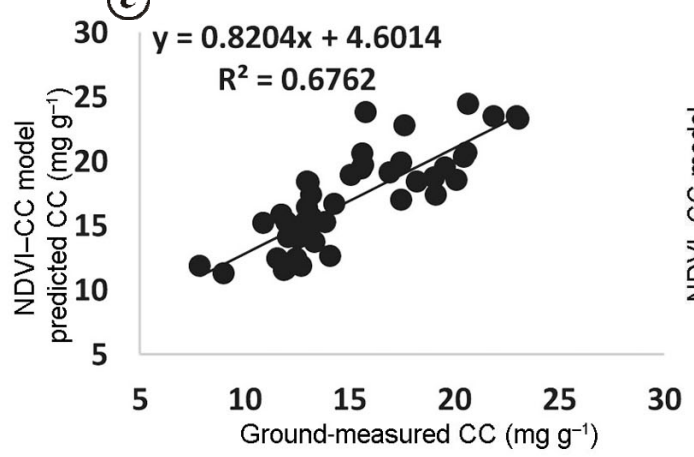

(b)

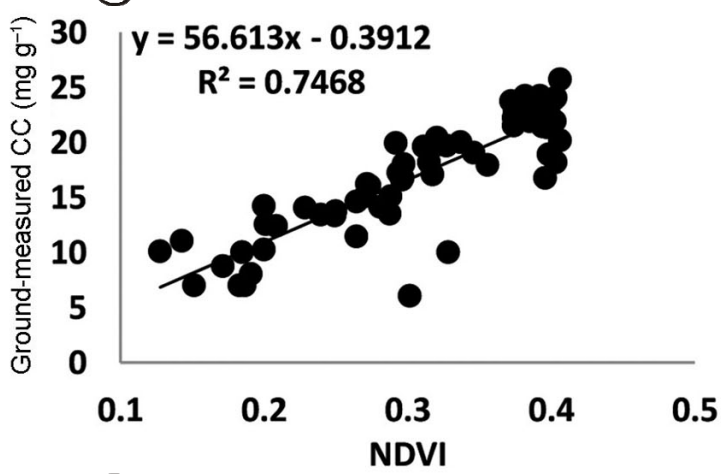

(d)

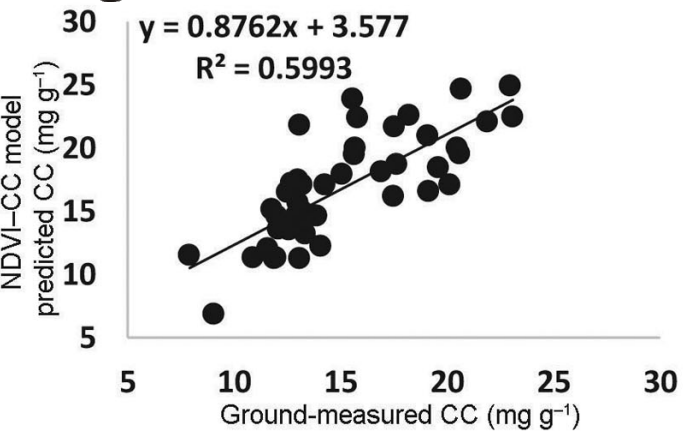

Figure 5. $\boldsymbol{a}$, Linear relationship between LANDSAT 5 TM NDVI and cotton chlorophyll content (CC); $\boldsymbol{b}$, Linear relationship between LISS-IV NDVI and cotton CC; $\boldsymbol{c}$, Validation of LANDSAT NDVI-CC model using ground-measured cotton CC; $\boldsymbol{d}$, Validation of LISS-IV NDVI-CC model using ground-measured cotton CC. 
(a)

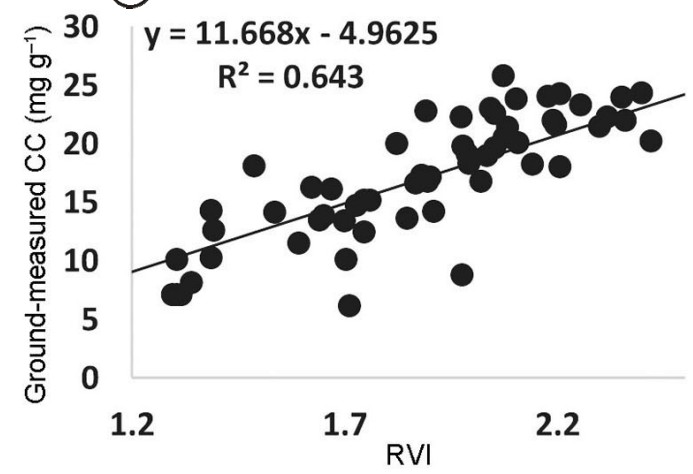

(c) $\mathrm{y}=0.7466 \mathrm{x}+5.5774$

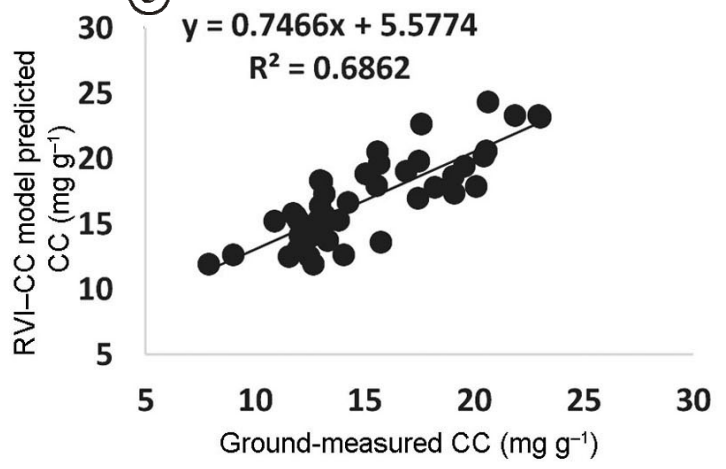

(b)
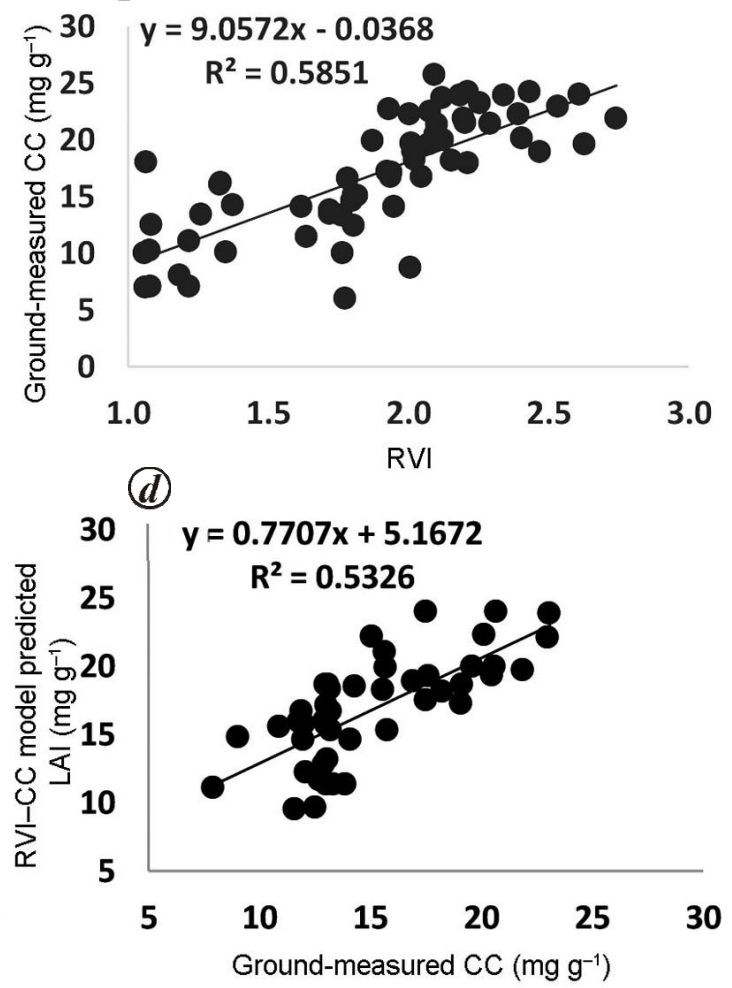

Figure 6. $\boldsymbol{a}$, Linear relationship between LANDSAT 5 TM-derived RVI and cotton CC; $\boldsymbol{b}$, Linear relationship between LISS-IV RVI and cotton CC; $\boldsymbol{c}$, Validation of Landsat RVI-CC model using ground-measured cotton CC; $\boldsymbol{d}$, Validation of LISS-IV RVI$\mathrm{CC}$ model using ground-measured cotton CC.

Table 3. Empirical-statistical relationships between cotton leaf area index (LAI) and optical RS-derived vegetation indices

\begin{tabular}{lllll}
\hline Parameter & Index & Satellite data & \multicolumn{1}{c}{ Fitting formula } & $R^{2}$ \\
\hline LAI & NDVI & LANDSAT TM & LAI $=11.476 \mathrm{NDVI}-0.2567$ & 0.6747 \\
& & LISS-IV & LAI $=12.088 \mathrm{NDVI}-0.6207$ & 0.8056 \\
& RVI & LANDSAT TM & LAI $=2.302 \mathrm{RVI}-1.2409$ & 0.5922 \\
& & LISS-IV & LAI $=2.8691 \mathrm{RVI}-2.7463$ & 0.6965 \\
Chlorophyll content $(\mathrm{CC})$ & NDVI & LANDSAT TM & CC $=56.753 \mathrm{NDVI}+0.4385$ & 0.6973 \\
& & LISS-IV & CC $=56.613 \mathrm{NDVI}-0.3912$ & 0.7468 \\
& \multirow{2}{*}{ RVI } & LANDSAT TM & CC $=11.668 \mathrm{RVI}-4.9625$ & 0.643 \\
& & LISS-IV & CC $=9.0572 \mathrm{RVI}-0.0368$ & 0.5851 \\
\hline
\end{tabular}

data showed an accuracy of $92.6 \%$ and that established using LISS-IV data showed an accuracy of $87.8 \%$.

NDVI-CC model: A positive and comparatively higher correlation was obtained between pigment CC and LISSIV NDVI with $R^{2}=0.746$, when compared to that between leaf $\mathrm{CC}$ and LANDSAT NDVI with $R^{2}=0.697$ (Figure $5 a$ and $b$ ). NDVI-CC models when validated showed good correlation between ground measured $\mathrm{CC}$ and predicted CC (Figure $5 c$ and $d$ ). Accuracies for these models were estimated; for LANDSAT 5 TM data it was $85.4 \%$ and for LISS-IV data it was $82.9 \%$.
RVI-CC model: Fitted empirical regression relationships between CC and LANDSAT RVI showed good correlations with $R^{2}=0.643$ (Figure $6 a$ ). Fitted regression relationships for CC and LISS-IV RVI emphasized comparatively low correlations with $R^{2}=0.585$ (Figure $6 \mathrm{~b}$ ). Validation for these models showed good relationship between $\mathrm{CC}$ estimated on the ground and that predicted using RVI-CC model (Figure $6 c$ and $d$ ). Accuracy test for these RS-based models was found to be good. For LANDSAT data $90.2 \%$ accuracy was obtained while for LISS IV data $65.9 \%$ accuracy was obtained. 


\section{RESEARCH COMMUNICATIONS}

Based on $R^{2}$ values NDVI was seen to be more closely related to $\mathrm{CC}$ than RVI, highlighting the potential of the former in the estimation of CC.

LISS-IV data showed better potential for estimation of LAI and CC when compared to LANDSAT 5 TM data, except for LISS-IV RVI-CC model. Comparison of $R^{2}$ values between the models revealed that NDVI was slightly superior to RVI in its correlation with crop foliar traits in both LANDSAT 5 TM and LISS-IV data (Table 3). Hence, NDVI-LAI and NDVI-CC models proved to be better for estimation of these traits. This may be due to the relatively lower insensitivity of NDVI to background soil reflectance and greater sensitivity of RVI to this factor $^{47}$. Moreover, NDVI is less affected by atmospheric conditions and topographical variations, while RVI is affected the most by atmospheric haze and topography. A relative disadvantage of NDVI is its saturation at higher LAI values ${ }^{48-54}$ compared to RVI, which indicates the inappropriateness of NDVI in the discrimination of crops with high-density cover or LAIs ${ }^{55,56}$.

In the present work, NDVI and RVI were used to retrieve foliar traits, viz. LAI and $\mathrm{CC}$ by developing empirical models. It is well known that there exists a strong correlation relationship between NDVI and RVI values. A simple linear regression model has been used in this analysis for estimation of crop foliar traits using optical satellite data, as these methods have been found to be fast and easily implementable for the large datasets. The models developed from both LANDSAT 5 TM and LISS-IV data for cotton showed good performance. In terms of indices, NDVI and in terms of data, LISS-IV exhibited better potential in the retrieval of foliar traits.

1. Asner, G. P., Biophysical and biochemical sources of variability in canopy reflectance. Remote Sensing Environ., 1998, 64, 234253.

2. Houborg, R., Soegaard, H. and Boegh, E., Combining vegetation index and model inversion methods for the extraction of key vegetation biophysical parameters using Terra and Aqua MODIS reflectance data. Remote Sensing Environ., 2007, 106(1), 39-58.

3. Watson, D. J., Comparative physiological studies in the growth of field crops. I. Variation in net assimilation rate and leaf area between species and varieties, and within and between years. Ann. Bot., 1947, 11, 41-76.

4. Bonan, G., Importance of leaf area index and forest type when estimating photosynthesis in boreal forests. Remote Sensing Environ., 1993, 43(3), 303-314.

5. Turner, D. P., Cohen, W. B., Kennedy, R. E., Fassnacht, K. S. and Briggs, J. M., Relationships between leaf area index, fAPAR, and net primary production of terrestrial ecosystems. Remote Sensing Environ., 1999, 70, 52-68.

6. Buermann, W., Dong, J., Zeng, X., Myneni, R. B. and Dickinson, R. E., Evaluation of the utility of satellite-based vegetation leaf area index data for climate simulations. J. Climate, 2001, 14, 3536-3550.

7. Dash, J., Curran, P. J. and Foody, G. M., Remote sensing of terrestrial chlorophyll content. In Global Climatology and Ecodynamics: Anthropogenic Changes to Planet Earth, Springer, Berlin, Heidelberg, 2009, pp. 77-105.
8. Singh, D. B., Malhi, R. K. M. and Kiran, G. S., Assessing the impact of agronomic spacing conditions on biophysical and biochemical parameters along with yield and yield components in cotton. IJAAR, 2015, 6(1), 36-44.

9. Blackburn, G. A., Hyperspectral remote sensing of plant pigments. J. Exp. Bot., 2007, 58(4), 855-867.

10. Collins, W., Remote sensing of crop type and maturity. Photogramm. Eng. Remote Sensing, 1978, 44(1), 43-55.

11. Milton, N. M. and Mouat, D. A., Remote sensing of vegetation responses to natural and cultural environment conditions. Photogramm. Eng. Remote Sensing, 1989, 55, 1167-1173.

12. Curran, P. J., Dungan, J. L. and Gholz, H. L., Exploring the relationship between reflectance red edge and chlorophyll content in splash pine. Tree Physiol., 1990, 7, 33-48.

13. Filella, I., Serrano, L., Serra, J. and Penuelas, J., Evaluating wheat nitrogen status with canopy reflectance indices and discriminant analysis. Crop Sci., 1995, 35(5), 1400-1405.

14. Everitt, J. H., Richardson, A. J. and Gausman, H. W., Leaf reflectance-chlorophyll relations in buffelgrass. Photogramm. Eng. Remote Sensing, 1985, 51, 436-466.

15. Muñoz-Huerta, R., Guevara-Gonzalez, R., Contreras-Medina, L., Torres-Pacheco, I., Prado-Olivarez, J. and Ocampo-Velazquez, R., A review of methods for sensing the nitrogen status in plants: advantages, disadvantages and recent advances. Sensors, 2013, 13(8), 10823-10843.

16. Moran, J. A., Mitchell, A. K., Goodmanson, G. and Stockburger, K. A., Differentiation among effects of nitrogen fertilization treatments on conifer seedlings by foliar reflectance: a comparison of methods. Tree Physiol., 2000, 20(16), 1113-1120.

17. Martinez, B., Cassiraga, E., Camacho, F. and Garcia-Haro, J., Geostatistics for mapping leaf area index over a cropland landscape: efficiency sampling assessment. Remote Sensing, 2010, 2, 2584-2606.

18. Pandya, M. R., Singh, R. P., Chaudhari, K. N., Bairagi, G. D., Sharma, R., Dadhwal, V. K. and Parihar, J. S., Leaf area index retrieval using IRS LISS-III sensor data and validation of the MODIS LAI product over Central India. IEEE Trans. Geosci. Remote Sensing, 2006, 44(7), 1858-1965.

19. Goel, N. S. and Strebel, D. E., Inversion of vegetation canopy reflectance models for estimating agronomic variables I: problem definition and initial results using the Suits' model. Remote Sensing Environ., 1983, 13(6), 487-507.

20. Goel, N. S., Models of vegetation canopy reflectance and their use in estimation of biophysical parameters from reflectance data. Remote Sensing Rev., 1988, 4(1), 1-212.

21. Privette, J. L., Myneni, R. B., Tucker, C. J. and Emery, W. J., Invertibility of a 1-D discrete ordinates canopy reflectance model. Remote Sensing Environ., 1994, 48(1), 89-105.

22. Myneni, R. B., Nemani, R. R. and Running, S. W., Estimation of global leaf area index and absorbed PAR using radiative transfer models. IEEE Trans. Geosci. Remote Sensing, 1997, 35(6), 1380-1393.

23. Jacquemoud, S., Bacour, H., Poilve, H. and Frangi, J. P., Comparison of four radiative transfer models to simulate plant canopies reflectance: direct and inverse mode. Remote Sensing Environ., 2000, 74, 417-481.

24. Zarco-Tejada, P. J., Miller, J. R., Morales, A., Berjon, A. and Aguera, J., Hyperspectral indices and model simulation for chlorophyll estimation in open-canopy tree crops. Remote Sensing Environ., 2004, 90, 463-476.

25. Schaepman, M. E., Koetz, B., Schaepman-Strub, G. and Itten, K. I., Spectrodirectional remote sensing for the improved estimation of biophysical and chemical variables: two case studies. Int. J. Appl. Earth Obs. Geoinf., 2005, 6(3-4), 271-282.

26. Houborg, R. and Boegh, E., Mapping leaf chlorophyll and leaf area index using inverse and forward canopy reflectance modeling and SPOT reflectance data. Remote Sensing Environ., 2008, 112(1), 186-202. 


\section{RESEARCH COMMUNICATIONS}

27. Yao, Y., Liu, Q., Liu, Q. and Li, X., LAI retrieval and uncertainty evaluations for typical row-planted crops at different growth stages. Remote Sensing Environ., 2008, 112(1), 94-106.

28. Asrar, G., Fuchs, M., Kanemasu, E. T. and Hatfield, J. L., Estimating absorbed photosynthetic radiation and leaf area index from spectral reflectance in wheat. Agron. J., 1984, 76, 300-306.

29. Curran, P. J. and Williamson, H. D., Airborne MSS data to estimate GLAI. Int. J. Remote Sensing, 1987, 8, 57-74.

30. Chen, J. M. and Cihlar, J., Retrieving leaf area index of boreal conifer forests using landsat TM images. Remote Sensing Environ., 1996, 55, 153-162.

31. Franklin, S. E., Lavigne, M. B., Deuling, M. J., Wulder, M. A. and Hunt, E. R., Estimation of forest leaf area index using remote sensing and GIS data for modeling net primary production. Int. J. Remote Sensing, 1997, 18, 3459-3471.

32. Kuusk, A., Monitoring of vegetation parameters on large areas by the inversion of a canopy reflectance model. Int. J. Remote Sensing, 1998, 19(15), 2893-2905.

33. Daughtry, C. S. T., Walthall, C. L., Kim, M. S., Brown de Colstoun, E. and McMurtrey III, G. E., Estimating corn leaf chlorophyll concentration from leaf and canopy reflectance. Remote Sensing Environ., 2000, 74(2), 229-239.

34. le Maire, G., Francois, C. and Dufrene, E., Towards universal broad leaf chlorophyll indices using PROSPECT simulated database and hyperspectral reflectance measurements. Remote Sensing Environ., 2004, 89(1), 1-28.

35. Xavier, A. C. and Vettorazzi, C. A., Mapping leaf area index through spectral vegetation indices in a subtropical watershed. Int. J. Remote Sensing, 2004, 25(9), 1661-1672.

36. Wang, F., Huang, J, Tang, Y. and Wang, X., New vegetation index and its application in estimating leaf area index of rice. Rice Sci., 2007, 143, 195-203.

37. Patil, S. S., Patil, V. C., Patil, B. N. and Patil, P. L., Simple yield prediction models to estimate wheat production. In The Third National Conference on Agro-Informatics and Precision Agriculture 2012 (AIPA 2012), IIT Hyderabad, Hyderabad, 1-3 August 2012, pp. 162-166.

38. Welles, J. M. and Norman, J. M., Instrument for indirect measurement of canopy architecture. Agron. J., 1991, 83, 818-825.

39. Arnon, D. I., Copper enzymes in isolated chloroplasts. Polyphenoloxidase in Beta vulgaris. Plant Physiol., 1949, 24(1), 1-15.

40. Wu, C., Niu, Z., Tang, Q. and Huang, W., Estimating chlorophyll content from hyperspectral vegetation indices: modeling and validation. Agric. For. Meteorol., 2008, 148(8-9), 1230-1241.

41. Pax-Lenney, M. and Woodcock, C. E., Monitoring agricultural lands in Egypt with multitemporal landsat TM imagery: how many images are needed? Remote Sensing Environ., 1997, 59(3), 522529.

42. Heller, E., Rhemtulla, J. M., Lele, S., Kalacska, M., Badiger, S., Sengupta, R. and Ramankutty, N., Mapping crop types, irrigated areas, and cropping intensities in heterogeneous landscapes of southern India using multi-temporal medium-resolution imagery: implications for assessing water use in agriculture. Photogramme. Eng. Remote Sensing, 2012, 78(8), 815-827.

43. Dong, J., Nai-Bin, W., Xiao-Huan, Y. and Ji-Hua, W., Study on the interaction between NDVI profile and the growing status of crops. Chin. Geogr. Sci., 2003, 13(1), 62-65.

44. Ji-Hua, M. and Bing-Fang, W., Study on the crop condition monitoring methods with remote sensing. Int. Arch. Photogramm., Remote Sensing Spat. Inf. Sci., 2008, XXXVII(B8), 945-950.

45. Meng, J., Du, X. and Wu, B., Generation of high spatial and temporal resolution NDVI and its application in crop biomass estimation. Int. J. Digit. Earth, 2013, 6(3), 203-218.

46. Mohan, S., Das, A., Maity, S., Mehta, R. L. and Haldar, D., ALOS RA: evaluation of polarimetric, interferometric and differential interferometric techniques for vegetation and land subsidence study. Final Project Report, ISRO, 2011, pp. 1-32.
47. Nayak, S. S., Thermal imagery and spectral reflectance based system to monitor crop condition. M Sc thesis, Texas Tech University, USA, 2005, pp. 1-107.

48. Ludeke, M., Janecek, A. and Kohlmaier, G. H., Modelling the seasonal $\mathrm{CO}_{2}$ uptake by land vegetation using the global vegetation index. Tellus B, 1991, 43(2), 188-196.

49. Gitelson, A. A., Wide dynamic range vegetation index for remote quantification of biophysical characteristics of vegetation. J. Plant Physiol., 2004, 161(2), 165-173.

50. Gonzalez-Dugo, M. and Mateos, L., Spectral vegetation indices for estimating cotton and sugarbeet evapotranspiration. Earth observation for vegetation monitoring and water management. In AIP Conference Proceedings, 2006, vol. 852, pp. 115-123.

51. Le Maire, G., Francois, C., Soudani, K., Davi, H., Dantec, V. L., Saugier, B. and Dufrene, E., Forest leaf area index determination: a multiyear satellite-independent method based on within-stand normalized difference vegetation index spatial variability. J. Geophys. Res., 2006, 111(G2), G02027.

52. Ferrara, R. M., Fiorentino, C., Martinelli, N., Garofalo, P. and Rana, G., Comparison of different ground-based NDVI measurement methodologies to evaluate crop biophysical properties. Ital. J. Agron., 2010, 5(2), 145-154.

53. Herrmann, I., Pimstein, A., Karnieli, A., Cohen, Y., Alchanatis, V. and Bonfi, J. D., Assessment of leaf area index by the red-edge inflection point derived from VEN $\mu S$ bands. In Proceedings of the ESA Hyperspectral Workshop, Frascati, Italy, 2010, vol. 683, pp. $1-7$.

54. Zhao, J., Lia, J., Liua, Q. and Yang, L., A preliminary study on mechanism of LAI inversion saturation. Int. Arch. Photogramm., Remote Sensing Spat. Inf. Sci., 2012, XXXIX(B1), 77-81.

55. Srinivas, P., Das, B. K., Saibaba, J. and Krishnan, R., Application of distance based vegetation index for agricultural crops discrimination. In XXth ISPRS Congress, Technical Commission VII, Istanbul, Turkey, 2004, pp. 1-6.

56. Chaurasia, S. et al., Development of regional wheat VI-LAI models using resourcesat-1 AWiFS data. J. Earth Syst. Sci., 2011, 120(6), 1113-1125.

57. Rouse, J. W., Haas, R. H., Schell, J. A. and Deering, D. W., Monitoring vegetation systems in the Great Plains with ERTS. In Third Earth Resources Technology Satellite-1 Symposium (eds Freden, S. C., Mercanti, E. P. and Becker, M.), Technical Presentations, NASA SP-351, NASA, Washington, D.C., 1974, vol. 1, pp. 309317.

58. Pearson, R. L. and Miller, L. D., Remote mapping of standing crop biomass for estimation of the productivity of the shortgrass prairie. In Proceedings of the 8th International Symposium on Remote Sensing of the Environment II, Pawnee National Grasslands, Colorado, 1972, pp. 1355-1379.

ACKNOWLEDGEMENTS. We thank The Maharaja Sayajirao University of Baroda, Vadadora for providing research facilities and financial assistance. We thank DRS and FIST for support. We also thank SAC, ISRO for technical help.

Received 22 May 2017; revised accepted 25 March 2019

doi: $10.18520 / \mathrm{cs} / \mathrm{v} 116 / \mathrm{i} 12 / 2089-2096$ 